\title{
Surgical Planning for Resection and Reconstruction of Facial Cutaneous Malignancies
}

\author{
${ }^{1}$ Evren Erkul, ${ }^{2}$ Krishna G Patel, ${ }^{3}$ Terry Day
}

\begin{abstract}
Skin cancer can be categorized into cutaneous melanoma and nonmelanoma skin cancer (NMSC). The latter includes such histologies as Merkel cell carcinoma (MCC), basal cell carcinoma (BCC), and squamous cell carcinoma (SCC). Of these, BCC and SCC are the most common skin cancers of the head and neck while malignant melanoma is the most aggressive. Sunscreen protection and early evaluation of suspicious areas remain the first line of defense against all skin cancers. When prevention fails, the gold standard of skin cancer management involves a multidisciplinary approach which takes into account tumor location, stage and biology of disease, and availability of resources. Proper diagnosis, staging, and treatment planning must all be addressed prior to initiating interventions. When surgery is indicated, facial reconstruction is a key aspect of the overall treatment plan and requires informed forethought as well as experience and skill. Here, we present an overview of surgical reconstruction recommendations and considerations for the subsites involved in head and neck skin cancer.
\end{abstract}

Keywords: Cutaneous, Facial, Reconstruction, Skin cancer, Surgical, Treatment.

How to cite this article: Erkul E, Patel KG, Day T. Surgical Planning for Resection and Reconstruction of Facial Cutaneous Malignancies. Int J Head Neck Surg 2016;7(3):149-164.

Source of support: Nil

Conflict of interest: None

\section{INTRODUCTION}

Skin cancer is the most commonly diagnosed cancer worldwide and the most commonly diagnosed cancer site in the United States and Australia. ${ }^{1-3}$ Skin cancer has often been categorized into broad categories of melanoma and nonmelanoma skin cancer (NMSC). Squamous cell

\footnotetext{
${ }^{1}$ Associate Professor, ${ }^{2}$ Clinical Research Fellow, ${ }^{3}$ Wendy and Keith Wellin Endowed Chair, Professor and Director

${ }^{1}$ Department of Otolaryngology-Head and Neck Surgery, Medical University of South Carolina, Charleston, South Carolina USA; Gulhane Military Medical Academy, Haydarpasa Training Hospital, Istanbul, Turkey

2,3Department of Otolaryngology-Head and Neck Surgery, Medical University of South Carolina, Charleston, South Carolina, USA

Corresponding Author: Terry Day, Wendy and Keith Wellin Endowed Chair, Professor and Director, Department of Otolaryngology Head and Neck Surgery, Medical University of South Carolina, Charleston, South Carolina, USA, Phone: +18437928363, e-mail: headneck@musc.edu
}

carcinoma (SCC) and basal cell carcinoma (BCC) are the most common types of NMSC, although other less common cutaneous malignancies are well known and may include Merkel cell carcinoma (MCC), angiosarcoma, and various malignancies of the adnexal structures. Currently, the NCCN guidelines list melanoma, nonmelanoma, and Merkel cell as the only separate categories for cutaneous malignancy with dedicated guidelines. Surgery remains the mainstay of treatment of skin cancers of the head and neck region. Surgical resection and reconstruction planning is vital to outcomes but can be difficult to standardize due to the diverse structures in the region, variability in nodal metastases, and various specialists diagnosing and treating these malignancies.

\section{EPIDEMIOLOGY}

The facial region is the most common site of skin cancer in the body and the head and neck is the region most frequently affected by NMSC. ${ }^{4}$ In the general population, BCC is more common than SCC by a factor of $4: 1$. $^{1,4}$ Unfortunately, there is no consensus on the definitions of the head and neck skin cancer sites due to differences in use of general terminology; this makes it difficult to compare studies with each other. Nonmelanoma skin cancer is most frequently found in sun-exposed areas of the body, which consist of the nose, cheeks, orbital area, and ears. ${ }^{4-6}$ Cutaneous melanoma in the head and neck region constitutes $20 \%$ of all melanomas and is most often seen in the face, scalp, and neck. ${ }^{7}$ In one study, the density of melanoma was five times as high on the face and four times as high on the ears compared with the body as a whole; for BCC and SCC the density of lesions was 12 to 15 times higher on the face and ears compared with the whole body. ${ }^{8}$ These facts make it very apparent that facial cutaneous malignancies represent a significant health burden and possibly the highest cosmetic, functional, and life-threatening site of skin cancers in the United States and the world.

Worldwide, it is difficult to estimate the total number of skin cancers but 3.3 million cases were estimated to be diagnosed as NMSC in the United States in 2012. Up to $1 \%$ of all skin cancers are considered to be cutaneous melanoma and it is now estimated that new cases of melanoma in 2016 will total 76,380 in the United States. ${ }^{1}$ The highest incidence of NMSC is in Australia followed 


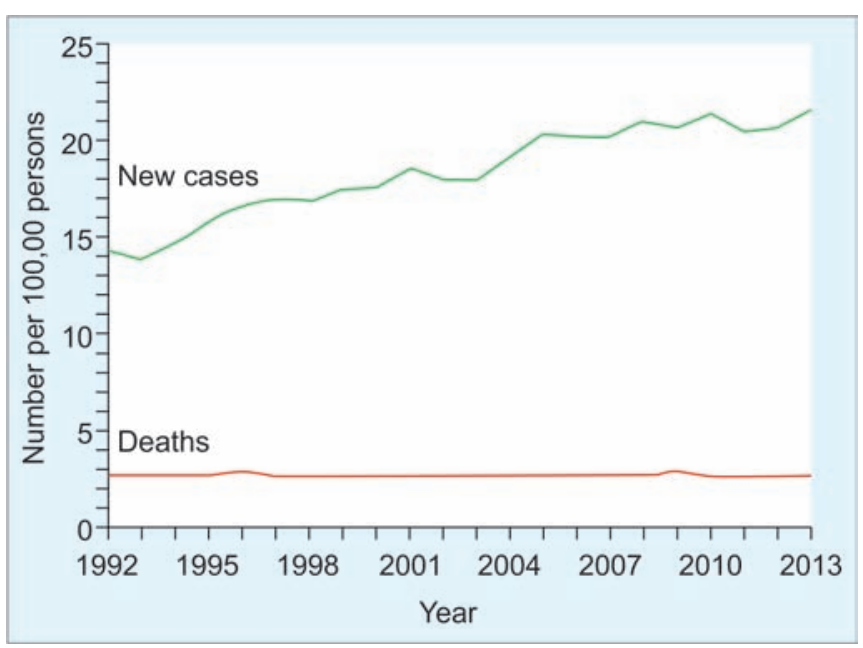

Graph 1: The increasing trend of the melanoma of the skin [The Surveillance, Epidemiology, and End Results (SEER) 2016 http:// seer.cancer.gov/statfacts/html/melan.html]

by the European countries and the United States. ${ }^{2}$ In addition, studies have revealed an increasing incidence of skin cancers (Graph 1). Rogers et $\mathrm{al}^{3}$ recently reported the incidence estimate for NMSC in the United States and this group also showed increasing trends by studying the Medicare population. Specifically, they found that there was an increase of $14 \%$ from 2006 to 2012 for NMSC patients. $^{3}$

\section{STAGING}

The tumor, node, metastasis (TNM) staging systems, recommended by the American Joint Committee on Cancer Staging, are based on retrospective data and use the end points of recurrence and survival. There is one system for NMSC, one for MCC, and one for melanoma. The current T system for NMSC classifies patients based on the size of primary tumor, as well as presence or absence of high-risk features, and invasion into underlying structures. The $\mathrm{N}$ classification examines size and number of lymph node metastases in the ipsilateral and contralateral sides of the primary disease site. The $\mathrm{M}$ classification indicates the presence or absence of distant metastatic disease. Staging MCC is similar, but incorporates few variables outside of size of tumor, extent of lymph node involvement, and presence or absence of metastasis. The melanoma staging system is an excellent example of how specific disease attributes can be integrated into staging. Here, a combination of the clinical and pathological findings is used and includes thickness, ulceration, and mitosis for the $\mathrm{T}$ classification, micrometastasis, macrometastasis, and satellite growth in $\mathrm{N}$ classification, and serum lactate dehydrogenase (LDH) in M classification. The 7th edition of the staging systems for melanoma and NMSC are shown in Tables 1 and 2.,10
Table 1: Tumor, node, metastasis staging for cutaneous SCC and other cutaneous carcinoma based on the American Joint Committee on Cancer Staging Manual ${ }^{9}$
Tumor $(T)^{\star}$
TX Primary tumor cannot be assessed
TO No evidence of primary tumor
Tis Carcinoma in situ
T1 Tumor $\leq 2 \mathrm{~cm}$ in greatest dimension with fewer than two high-risk features ${ }^{\star *}$
T2 Tumor $>2 \mathrm{~cm}$ in greatest dimension or tumor of any size with two or more high-risk features
T3 Tumor with invasion of maxilla, mandible, orbit, or temporal bone
T4 Tumor with invasion of skeleton (axial or appendicular) or perineural invasion of skull base
Node (N)
NX Regional lymph nodes cannot be assessed
NO No regional lymph node metastases
$\mathrm{N} 1$ Metastasis in a single ipsilateral lymph node, $\leq 3 \mathrm{~cm}$ in greatest dimension
N2 Metastasis in a single ipsilateral lymph node, $>3 \mathrm{~cm}$ but not $>6 \mathrm{~cm}$ in greatest dimension; or in multiple ipsilateral lymph nodes, none $>6 \mathrm{~cm}$ in greatest dimension; or in bilateral or contralateral lymph nodes, none $>6 \mathrm{~cm}$ in greatest dimension $\mathrm{N} 2 \mathrm{a}$ Metastasis in a single ipsilateral lymph node, $>3 \mathrm{~cm}$ but not $>6 \mathrm{~cm}$ in greatest dimension
$\mathrm{N} 2 \mathrm{~b}$ Metastasis in multiple ipsilateral lymph nodes, none $>6 \mathrm{~cm}$ in greatest dimension
N2C Metastasis in bilateral or contralateral lymph nodes, none $>6 \mathrm{~cm}$ in greatest dimension
N3 Metastasis in a lymph node, $>6 \mathrm{~cm}$ in greatest dimension
Metastasis (M)
MO No distant metastasis
M1 Distant metastasis

*Excludes cutaneous SCC of the eyelid; **High-risk features for the primary tumor (T) staging: (1) Depth/invasion: $>2 \mathrm{~mm}$ thickness, Clark level >IV, or perineural invasion; (2) anatomical location: Primary site ear, or primary site non-hair bearing lip; (3) differentiation: Poorly differentiated or undifferentiated

\section{ETIOPATHOGENESIS}

\section{Nonmelanoma Skin Cancer}

There are several important factors involved in the pathogenesis of skin cancers and the major risk factor is high exposure to ultraviolet (UV) radiation from sunlight or indoor tanning. ${ }^{1,4}$ Ultraviolet radiation has long been known to be the most important etiological factor in the pathogenesis of NMSC. In 1992 the International Agency for Research on Cancer classified solar radiation as a group one carcinogenic hazard that is known to cause cancer in people. ${ }^{11}$ Patients that live in areas with higher temperatures, more sun exposure, sunburn, and exposed skin are more likely to have an NMSC. ${ }^{2}$ There is an increasing trend in NMSC numbers for patients greater than 60 years old; possible reasons related to this rise are both acute and prolonged UV exposure, increased detection, increase in outdoor activities, clothing style 
Table 2: Tumor, node, metastasis staging for melanoma based on the American Joint Committee on Cancer Staging Manual ${ }^{10}$

Primary tumor (T)

TX Primary tumor cannot be assessed (e.g., curettage or severely regressed melanoma)

TO No evidence of primary tumor $\mathrm{T}$ in melanoma in situ

T1 Melanomas $1.0 \mathrm{~mm}$ or less in thickness

T2 Melanomas 1.01-2.0 mm

T3 Melanomas 2.01-4.0 mm

T4 Melanomas more than $4.0 \mathrm{~mm}$

Note: $\mathrm{a}$ and $\mathrm{b}$ subcategories of $\mathrm{T}$ are assigned based on ulceration and number of mitoses per $\mathrm{mm}^{2}$ as shown below:

\begin{tabular}{lll}
\hline T classification & Thickness $(\mathrm{mm})$ & Ulceration status/Mitoses \\
\hline T1 & $\leq 1.0$ & a: w/o ulceration and mitosis $<1 / \mathrm{mm}^{2}$ \\
& & b: with ulceration or mitoses $\geq 1 / \mathrm{mm}^{2}$ \\
T2 & $1.01-2.0$ & a: w/o ulceration b: with ulceration \\
T3 & $2.01-4.0$ & a: w/o ulceration b: with ulceration \\
T4 & $>4.0$ & a: w/o ulceration b: with ulceration \\
\hline
\end{tabular}

Regional Lymph Nodes (N)

NX Patients in whom the regional lymph nodes cannot be assessed

(e.g., previously removed for another reason)

NO No regional metastases detected

N1-N3 Regional metastases based on the number of metastatic nodes and presence or absence of intralymphatic metastases (in transit or satellite metastases)

Note: N1-N3 and a-c subcategories are assigned as shown below:

\begin{tabular}{|c|c|c|}
\hline N Classification & No. of metastatic nodes & Nodal metastatic mass \\
\hline & & a: micrometastasis* \\
\hline \multirow[t]{2}{*}{ N1 } & 1 Node & b: macrometastasis** \\
\hline & & a: micrometastasis* \\
\hline \multirow[t]{2}{*}{ N2 } & 2-3 Nodes & b: macrometastasis $\star \star$ \\
\hline & & c: in transit met(s)/satellite(s) without metastatic nodes \\
\hline N3 & $\begin{array}{l}4 \text { or more metastatic nodes, or matted } \\
\text { nodes, or in transit met(s)/satellite(s) with } \\
\text { meta-static node(s) }\end{array}$ & \\
\hline \multicolumn{3}{|c|}{$\begin{array}{l}{ }^{*} \text { Micrometastases are d } \\
\text { as clinically detectable } \\
\text { extracapsular extension }\end{array}$} \\
\hline \multicolumn{3}{|c|}{ Distant metastasis (M) } \\
\hline \multicolumn{3}{|c|}{ MO No detectable evidence of distant metastases } \\
\hline \multicolumn{3}{|c|}{ M1a Metastases to skin, subcutaneous, or distant lymph nodes } \\
\hline \multicolumn{3}{|c|}{ M1b Metastases to lung } \\
\hline \multicolumn{3}{|c|}{ M1c Metastases to all other visceral sites or distant metastases to any site combined with an elevated serum LDH } \\
\hline \multicolumn{3}{|c|}{ Note: Serum LDH is incorporated into the M category as shown below: } \\
\hline M Classification & Site & Serum $L D H$ \\
\hline M1a & Distant skin, subcutaneous, or nodal mets & Normal \\
\hline M1b & Lung metastases & Normal \\
\hline \multirow[t]{2}{*}{ M1c } & All other visceral metastases & Normal \\
\hline & Any distant metastasis & Elevated \\
\hline
\end{tabular}

changes, ozone depletion, and increasing numbers of older people in the population. ${ }^{12}$ However, acquired and inherited mutations, immunosuppression, smoking, and environmental carcinogenesis have been reported to play a role in the pathogenesis of NMSC in some patients. ${ }^{2,4}$ Skin type and ancestry are also well known to impact the onset of skin cancer, with fair-skinned people who tan poorly being more likely have NMSC than black or Asian people. ${ }^{4,13,14}$ Fair-skinned people with naturally blond or red hair color are in the highest risk group for NMSC. ${ }^{1,6,7}$ The risk of developing NMSC increases markedly with age and males are more commonly affected than females. ${ }^{1,4}$

In addition to excessive sun exposure and sunburns, chronic exposure to chemical carcinogens (arsenic), organ transplant, autoimmune disorders requiring immunosuppressive agents, chronic ulcers, scars, and sinus tracts are the other risk factors for NMSC. ${ }^{4,6,15}$ Skin cancers are the most common tumors in the transplant population, with $80 \%$ involving head and neck sites. ${ }^{15}$ The BCC and SCC account for more than $90 \%$ of all skin cancers and SCC is more common among transplant patients. The 
incidence of skin cancer is higher than in the general population. ${ }^{15}$

There are also two types of genetic syndromes: Xeroderma pigmentosa and nevoid BCC syndrome that confer an increased risk of developing NMSC., ${ }^{1,4}$,

\section{Melanoma}

Melanoma has a closer correlation with intermittent intense exposure to UV radiation compared to NMSC. ${ }^{1,4}$ Individuals who suffered blistering or other severe sunburn during childhood or adolescence appear to be at increased risk for developing a melanoma later in life. People with fair skin and naturally blond hair are also at increased risk. ${ }^{1,4,7}$ Additionally, personal or family history of melanoma and the presence of atypical and numerous moles are other risk factors. ${ }^{1,6,7}$

A melanoma of an unknown primary site is defined as a melanoma, i.e., first identified by its regional, nodal disease $(70 \%)$ or a distant site (30\%). Approximately, $10 \%$ of head and neck melanomas present as an unknown primary which is identified by nodal disease or a distant metastasis. ${ }^{7}$ These melanomas are thought to have developed from a primary that has since regressed or was overlooked. Although melanoma comprises only $5 \%$ of all skin cancers, more than three of four deaths from skin cancer are due to melanoma. ${ }^{4}$ In 2016, it is estimated that 10,130 deaths from melanoma and 3,520 deaths from other types of skin cancer will occur. ${ }^{1}$ Melanomas of the face have better survival rates than those of the scalp and neck, with 5-year survival exceeding $70 \%{ }^{7}$

\section{Merkel Cell Carcinoma}

Merkel cell carcinoma is a rare, neuroendocrine, cutaneous malignancy that mostly appears with aggressive features and is associated with a poor prognosis. ${ }^{16}$ The etiology is likely multifactorial with immunosuppression, UV-induced skin damage, and viral factors contributing. The head and neck is the most commonly affected region of the body. ${ }^{16}$ Males were found to be affected more commonly than females with the median age at diagnosis being in the $70 \mathrm{~s}{ }^{16}$ Merkel cell carcinoma can also often occur in patients with preexisting SCC or BCC.

\section{Angiosarcoma}

Angiosarcoma commonly occurs in the head and neck region and males are affected more than two times as frequently as females. ${ }^{17}$ One large study on angiosarcomas found a mean age at diagnosis of 71 years. ${ }^{17}$ Its possible risk factors are chemical exposure (vinyl chloride, thorium, arsenic) and radiation, and it has a poor survival rate with a 5 -year mortality of $28 \% .{ }^{17}$

\section{Other Cutaneous Malignancies of the Facial Region}

Malignancies may also arise from the adnexal structures of the skin with apocrine, eccrine, follicular, or sebaceous differentiation and all are rare, representing $<1 \%$ of cutaneous head and neck malignancies.

\section{Malignant Skin Adnexal Tumors}

Malignant skin adnexal tumors are a rare group of tumors and can be classified as tumors arising from as the pilo-sebaceous unit, eccrine and apocrine glands, and mixed tumors. ${ }^{18,19}$ The head and neck region is the commonest site for some types of these tumors. These tumors are mostly slow-growing tumors with a low rate of metastasis. ${ }^{18,19}$ In patients with mucinous carcinoma, apocrine carcinoma, and adenoid cystic carcinoma, investigations should be done to exclude a primary tumor arising from another organ. ${ }^{18}$ Wide local excision is the mainstay of treatment for malignant adnexal skin tumors. ${ }^{18}$ Most malignant skin adnexal neoplasms have a low rate of nodal metastasis. Radiation therapy (RT) should be considered in patients for whom surgery is contraindicated, or in the adjuvant setting where there are positive margins, or if perineural invasion is present. ${ }^{20}$ Sebaceous carcinoma is one type of malignant adnexal tumor and it arises over $70 \%$ of the time in the head and neck region. ${ }^{21}$ The eyelid is the commonest site and it grows slowly as firm nodules. An Erovic et $\mathrm{al}^{21}$ study has documented a $60 \%$ incidence of occult nodal metastases for this disease, and patients with lower eyelid lesions as having the worst prognosis. They, therefore, recommended consideration of prophylactic elective neck dissections.

\section{Sarcoma-like Tumors of Head and Neck Skin}

Atypical fibroxanthoma (AFX) and pleomorphic dermal sarcoma (PDS) predominantly occur in sun-damaged skin of the elderly, particularly in the head and neck region. ${ }^{22,23}$ Whites are most commonly affected, and there is male predominance. There are some close links between these tumors and SCC, and in some cases AFX/ PDS may represent complete dedifferentiation..$^{22}$ Recurrence and metastasis is rare and the treatment modality for these rare tumors should be excision with clear margins because the margin status appears to be the most important prognostic factor. ${ }^{22,23}$

\section{Physical Examination}

The most common finding in NMSC is a red lesion that may be raised, scaling, or ulcerated in the face or scalp. Although the patient may have noticed it, the diagnosis is most often made when a family member or primary 
care physician makes a referral to a dermatologist for biopsy. Any enlarging red, brown, or black ulcerative lesion of the face or scalp should be evaluated by a dermatologist or surgeon and biopsy should be performed as indicated. Most cases are diagnosed at an early stage and metastatic SCC is a rare entity $(<5 \%$ of cases $) .{ }^{4}$ The detailed medical history, any relevant disease, risk factors, and comorbidities should be evaluated. Superficial BCC may be a plaque or a papule and is pink/red in color. ${ }^{5}$ The SCC may appear as a rough surface with a growing lump or as a flat, red/pink color patch that grows slowly. Certain characteristics of melanoma are defined with the acronym "ABCDE" as Asymmetry, Border irregularity, Color variation, Diameter greater than $6 \mathrm{~mm}$, and Evolution which reflects high likelihood of being melanomas. ${ }^{7}$

Once a lesion has been identified and does not resolve spontaneously, a biopsy is indicated for pathologic examination. The biopsy is required to provide the clinician with the diagnosis, prognosis, and treatment guidelines. Histopathological investigation must be done for any suspicious lesion and the report of the biopsy is important for definitive diagnosis, treatment selection, and prognostication. Tissue sampling may be carried out as a shave biopsy using a scalpel across the surface, incisional, punch, or excisional biopsies. Shave biopsies have been controversial as they may not provide the full extent of the lesion or depth of invasion. Additionally, punch biopsies may not be wide enough to define all histological risk factors for SCC and melanoma. ${ }^{7}$ As the facial region has areas of great functional and cosmetic concern, such as the eyes, lips, nose, and ears, incisional or punch biopsy may be preferred. ${ }^{7}$ If a punch biopsy is necessary because of location, it should be performed in the thickest portion of the lesion. However, these findings cannot be considered definitive for the entire lesion as one part of a lesion may have different histology than an adjacent area. In one study, both punch biopsies and shave biopsies were successful in diagnosing BCC with an accuracy rate of 75 to $80 \% .{ }^{24}$ In contrast, Austin et al compared excisional biopsy and all other types of incisional biopsy. Comparing the survival rates and locoregional and distant metastasis in head and neck melanoma patients, they found that $31 \%$ of subjects who had an incisional biopsy died of disease, whereas only $8.9 \%$ of the excisional group died of disease. They suggest that the method of biopsy for cutaneous melanomas of the head and neck may influence the clinical outcome. ${ }^{25}$

The SCC may metastasize to regional lymph nodes found within the parotid gland, to the lateral and/or occipital nodes, or to cervical neck nodes; such spread is important for prognosis. Neck examination should be done for possible neck metastasis in all skin cancer patients. Fine-needle biopsy should be done if a patient with SCC has a palpable lymph node in head and neck or a suspicious lymphadenopathy is identified by imaging studies.

\section{Diagnostic Workup and Imaging}

For NMSC, such as BCC and SCC, biopsy is the initial step and if the lesion is small and in a low-risk area in a low-risk patient, the patient should not require additional workup or imaging. The patient would receive definitive therapy with surgery and/or radiation as appropriate. The type of surgery and margin assessment is important as all cutaneous malignancies should be treated with surgically clear margins. This often requires the surgeon to take circumferential margins and deep margins via Mohs technique or frozen section in order to assure that all cancer have been cleared. Any positive margins or cancer left behind should be considered for additional surgery or RT if unresectable.

Patients with high risk clinical or histological features will require more detailed investigations, including ultrasonography, computerized tomography (CT), magnetic resonance imaging (MRI), and positron emission tomography (PET) scanning for detection of regional and distant metastasis. ${ }^{4,7}$ High-risk patients include those with a recurrent or T3 or T4 SCC of the face or scalp, cancer in a high-risk subsite, or who are immunosuppressed; these will have a higher incidence of nodal and distant metastasis and also a higher risk of recurrence. Thus, these patients may require CT imaging of the parotid and neck to evaluate the deep extent of the tumor, including nerve, muscle, or bone involvement, and also to search for evidence of nodal metastasis. If the patient is at high risk, a CT/PET scan may be required to evaluate the patient for distant metastasis. The low-risk and high-risk classification of the patients with BCC and SCC are shown in Tables 3 and $4 .^{9,26}$

Table 3: Basal cell carcinoma risk classification

\begin{tabular}{lll}
\hline Risk factor & Low risk & High risk \\
\hline Location/size & Area $\mathrm{L}<20 \mathrm{~mm}$ & Area $\mathrm{L} \geq 20 \mathrm{~mm}$ \\
& Area $\mathrm{M}<10 \mathrm{~mm}$ & Area $\mathrm{M} \geq 10 \mathrm{~mm}$ \\
& Area $\mathrm{H}<6 \mathrm{~mm}$ & Area $\mathrm{H} \geq 6 \mathrm{~mm}$ \\
Borders & Well defined & Poorly defined \\
Primary or recurrent & Primary & Recurrent \\
Immunosuppression & - & + \\
Site of prior RT & - & + \\
Subtype & Nodular, superficial & Aggressive growth \\
Perineural involvement & - & + \\
\hline
\end{tabular}

Area $\mathrm{H}=$ "mask areas" of face (central face, eyelids, eyebrows, periorbital, nose, lips [cutaneous and vermilion], chin, mandible, preauricular and postauricular skin/sulci, temple, ear), genitalia, hands, and feet; Area $M=$ cheeks, forehead, scalp, neck, and pretibia; Area $\mathrm{L}=$ trunk and extremities (excluding pretibia, hands, feet, nail units, and ankles) 
Table 4: Squamous cell carcinoma risk classification ${ }^{9}$

\begin{tabular}{lll}
\hline Risk factor & Low risk & High risk \\
\hline Location/size & Area $\mathrm{L}<20 \mathrm{~mm}$ & Area $\mathrm{L} \geq 20 \mathrm{~mm}$ \\
& Area $\mathrm{M}<10 \mathrm{~mm}$ & Area $\mathrm{M} \geq 10 \mathrm{~mm}$ \\
& Area $\mathrm{H}<6 \mathrm{~mm}$ & Area $\mathrm{H} \geq 6 \mathrm{~mm}$ \\
Borders & Well defined & Poorly defined \\
Primary or recurrent & Primary & Recurrent \\
Immunosuppression & - & + \\
Site of prior RT or chronic & - & + \\
inflammatory process & & + \\
Rapidly growing tumor & - & + \\
Neurologic symptoms & - & + \\
$\begin{array}{l}\text { Degree of differentiation } \\
\text { Adenoid, adenosquamous, },\end{array}$ & - & + \\
desmoplastic or & & \\
basosquamous subtype & & \\
$\begin{array}{l}\text { Depth:Thickness or Clark } \\
\text { level }\end{array}$ & $<2 \mathrm{~mm}$ or I, II, III & $\geq 2 \mathrm{~mm}$ or IV, V \\
$\begin{array}{ll}\text { Perineural, lymphatic or } \\
\text { vascular involvement }\end{array}$ & - & \\
\hline
\end{tabular}

Area $\mathrm{H}=$ "mask areas" of face (central face, eyelids, eyebrows, periorbital, nose, lips [cutaneous and vermilion], chin, mandible, preauricular and postauricular skin/sulci, temple, ear), genitalia, hands, and feet; Area $M=$ cheeks, forehead, scalp, neck, and pretibia; Area $\mathrm{L}=$ trunk and extremities (excluding pretibia, hands, feet, nail units, and ankles)

Patients with cutaneous melanoma have various important diagnostic requirements to consider during the diagnosis and treatment phase. Initially, the biopsy should provide the dermatopathologist with adequate tissue to determine: Histology, immunohistochemistry, depth, ulceration, and mitoses count. Once the initial biopsy stage is provided, the patient may be a candidate for CT/PET, MRI of the brain, sentinel lymph node biopsy (SLNB), surgical resection, lymph node dissection with parotidectomy and/or neck dissection, RT, immunotherapy, and/or chemotherapy. The diagnosis and treatment of all melanomas should incorporate a multidisciplinary approach with a head and neck surgeon, dermatologist, medical oncologist, dermatopathologist, and radiation oncologist. Facial plastic and reconstructive surgery may be required for optimal function and cosmesis.

Recurrent cancers are hard to predict and the extent, depth, nerve involvement, margins, and metastatic potential is very difficult to assess. Almost all of these require evaluation by a head and neck surgeon and may require reconstructive surgery and/or adjuvant RT regardless of histologic type.

\section{Treatment Modalities}

Patients with skin cancers may be managed nonsurgically or surgically with or without reconstruction based on the relevant tumor and patient factors. Surgical excision is preferred as the first line treatment method for NMSC. Mohs surgery is a microscopically controlled procedure that allows maximal excision of involved tumor in cutaneous neoplasms while minimizing the excision of uninvolved tissue. It achieves this through mapping the surgical site and successive resection of tumor and subsequent histological analysis of resected borders until clear margins are achieved. ${ }^{6}$ No significant difference was seen in recurrence rate between patients receiving standard excision or Mohs surgery, and overall cosmetic outcome did not differ between treatment groups. However, total operative costs of Mohs surgery were higher than those of standard excision in facial BCC patients. ${ }^{27}$

The NCCN guidelines suggests that $4 \mathrm{~mm}$ margins for BCC and 4 to $6 \mathrm{~mm}$ margins for SCC are adequate for treatment in low-risk BCC and local SCC patients. ${ }^{28,29}$ Brodland and Zitelli ${ }^{29}$ and Wolf and Zitelli ${ }^{28}$ stated that excision with wider margins is recommended for highrisk patients with a primary or delayed repair. Low-risk SCC patients have a high cure rate when treated with Mohs or standard surgical excision, but high-risk tumors require treatment with Mohs micrographic surgery or wide complete excision with frozen section assessment. ${ }^{30}$

A positive margin(s) has been reported to be associated with a high local recurrence rate, and in many cases patients with positive margins should be considered for further surgery or adjuvant RT. ${ }^{29,30}$ Excision margins that are positive for tumor are associated with recurrent SCC in up to $50 \%$ of patients. ${ }^{31}$ An excision margin of $6 \mathrm{~mm}$ in patients with high-risk SCC is recommended. In one study, an excision margin of $4 \mathrm{~mm}$ for low and intermediate risk and $6 \mathrm{~mm}$ for high-risk SCC resulted in tumor clearance in 95 to $97 \%$ of cases. ${ }^{29}$ The long-term prognostic benefit of negative margins is highlighted by the results of Mohs micrographic surgery. In a multicenter Australian study with 1,263 patients, 5-year disease-free survival (DFS) was reported as $97.4 \%$ with $>95 \%$ of lesions located on the head and neck region. ${ }^{32}$ In cases where there is an extensive BCC that is unresectable or in an area that would result in a permanent life-threatening, cosmetic or functional disability, chemotherapy may be considered using Vismodegib. ${ }^{33}$ However, long-term results and outcomes are as yet unknown and surgery and/or reconstruction may still be necessary if persistent or recurrent disease exists.

External beam RT or brachytherapy may be recommended as definitive treatment when surgery is not optimal or possible for SCC patients. ${ }^{30}$ Surgery can be challenging when there are functional (size and site of the tumor) and/or cosmetic outcome (mid-face) concerns. However, RT for a cutaneous malignancy may result in necrosis or loss of function of the nose, eyes, ears, lips, or face. Thus, the patient may still require reconstructive surgery to remove the radiation and cancer damaged tissue. The risk of complications, such as necrosis and 
late ( $>5$ years) in-field cosmetic outcomes, possible need for future RT delivery to the same site, and small risk of in-field secondary malignancy risks, should be kept in mind when choosing the RT treatment, especially in younger patients. Petit et $\mathrm{al}^{34}$ compared RT vs excision of facial BCCs of $<40 \mathrm{~mm}$ in diameter and showed fewer recurrences, better cosmetic outcomes, and fewer complications in the surgical cohort at 4 years compared with the RT group. The risk of radiation also includes osteoradionecrosis and radiation-induced sarcoma. ${ }^{35,36}$

Approximately, 5\% of the NMSC (mostly SCC) patients may have poor prognostic factors which are related with recurrences and/or metastasis. ${ }^{37}$ These factors include locally advanced primary disease (stage T3-T4), regional nodal involvement, clinical perineural invasion, recurrent disease following treatment, and immunosuppression. Patients who have these features may require combined modality treatment involving surgery and adjuvant RT. ${ }^{37}$

Cryotherapy, photodynamic therapy, intralesional interferon, curettage and cautery, fluorouracil, imiquimod and Hedgehog-pathway inhibitors are the other nonsurgical options for NMSC treatment. ${ }^{4,6}$ Other nonsurgical treatment methods for NMSC have very limited support for evidence assessing the efficacy.

\section{Melanoma}

The gold standard for initial treatment of melanoma has always been surgical. Approaches with radiation, chemotherapy, immunotherapy alone or combinations are reserved for advanced and metastatic disease. Primary surgery is wide excision with the margin dictated by its thickness. ${ }^{7}$ There are always esthetic and functional sensitivities in the head and neck region which are distinct from the trunk and extremities. The NCCN guidelines for melanomas are as follows: $1.0 \mathrm{~mm}$ or less thickness requires a wide excision with a $1 \mathrm{~cm}$ margin, 1.01 to $2 \mathrm{~mm}$ in thickness requires a wide excision with a 1 to $2 \mathrm{~cm}$ margins, and more than $2 \mathrm{~mm}$ in thickness requires wide excision with $2 \mathrm{~cm}$ margins. ${ }^{10}$ Surgical margins may be modified to accommodate individual anatomic or cosmetic considerations. One to two centimeter might be acceptable in anatomically difficult areas where a full $2 \mathrm{~cm}$ margin would be difficult to achieve. ${ }^{10,38,39}$

For patients with stage III melanoma, adjuvant treatment options include clinical trial, observation, or interferon-alpha. ${ }^{10}$ Adjuvant RT may be considered for selected patients with clinically positive nodes. Decisions about adjuvant interferon treatment should be made on an individual basis, after a thorough discussion with the patient about the potential benefits and side effects of therapy. ${ }^{10}$

\section{Merkel Cell Cancer}

The primary mainstay of treatment in MCC is surgery with $10 \mathrm{~mm}$ margins, which is desirable in the head and neck region. Adjuvant RT therapy should be considered for patients with positive or close margins. ${ }^{16}$ Regional lymph nodes must be investigated and a SLNB should be considered. Patients should be considered for definitive RT alone in inoperable cases. ${ }^{16}$ The use of chemotherapy is less well defined for MCC. Chemotherapy is currently used in advanced stage MCC and as palliative therapy. There is no standard choice of chemotherapeutic agent. ${ }^{16}$

\section{Reconstruction}

The functional and esthetic importance of the face makes the reconstruction of defects after head and neck skin cancer resection unique and complex. The face has been described as the window to the soul. ${ }^{40}$ It is known to be important in social life and relationships, so planning the tumor resection of the head and neck skin cancer and the subsequent reconstruction includes three important factors: Surgeon perspective and experience, patient health status and expectations, and tumor features, such as shape, size, and thickness. ${ }^{41}$ As with many reconstructive endeavors, adequate results can be obtained with fewer steps; however, extra stages for flap thinning, contour refinement, and scar revision invariably result in better esthetic outcomes. It is useful when planning such treatment to tailor the refinement to the expectations of the patient and his or her suitability for multiple operations.

\section{MANAGEMENT OF THE PATIENT WITH A NEW SKIN CANCER}

\section{Initial Visit}

\section{History}

Surgical and reconstructive planning begins with a thorough history and physical examination. The history should include the clinical presentation with signs and symptoms related to the lesion of interest. The clinical growth of the lesion, any prior biopsies and/or treatment is crucial information for managing the patient. Prior treatments and/or biopsies should be requested for a secondary review of diagnosis, margin status, and other pathologic indicators. Additionally, any past reconstruction performed for a biopsy or treatment may complicate margin clearance and future reconstruction. Once the prior biopsy or surgery or pathology report is received, the surgeon should review the records for potential close or positive margins, risk factors for metastasis, and details of the histopathologic diagnosis. 
It is important to assess for prior skin cancers as UV exposure often results in multifocal disease and at-risk patients are often at high risk for new lesions or recurrence. There are known comorbidities including smoking history, prior radiation, immunosuppression, and diabetes that may place an individual at higher risk for advanced disease, recurrence, or poor healing.

Finally, since the head and neck region incorporates many structures involved in activities of daily living including vision, eating, drinking, speaking, chewing, breathing, smiling, and many others, the surgeon should understand a patient's expectations, goals, occupation, hobbies, and interests. These should be taken into account during treatment and reconstruction planning.

\section{Physical Examination}

The patient should undergo a full head and neck physical examination in addition to full body examination, including potential flap or graft donor sites. The physical examination should include all scalp, face and neck lesions, prior scars, skin grafts, and lymph node basins. Cranial nerve examination and sensory/motor function tests should be performed in all patients with head and neck skin cancers. Any sensory or motor deficits should alert the physicians to the potential for perineural spread and necessitate imaging, such as MRI and/or CT/PET scanning. Photographic documentation, measurements, and palpation are helpful in planning.

\section{Imaging}

Routine imaging of cutaneous malignancies is not recommended. 9,10,26,42 However, any patient with recurrence in an operated bed, deep extension, large mass, regional lymph nodes, or neurogenic symptoms should undergo further evaluation with imaging. ${ }^{9,10}$ In these scenarios, CT scanning with and without contrast, MRI with gadolinium, and CT/PET scanning are commonly used. ${ }^{9,10,42}$

\section{MANAGEMENT OF REGIONAL LYMPH NODES}

\section{Sentinel Lymph Node Biopsy and Neck Dissection}

\section{Squamous Cell Carcinoma}

Squamous cell carcinoma may result in nodal metastasis in only $4 \%$ of patients, so SLNB for clinically no patients is not justified and there is no conclusive evidence of its prognostic or therapeutic value. ${ }^{43,44}$ In recent years, some studies have suggested the utility of SLNB for high-risk SCC. ${ }^{45}$

Patients with palpable or suspicious lymph nodes on imaging should receive a fine-needle biopsy; if a there is negative initial biopsy, the patient should be re-evaluated. ${ }^{9}$
If findings of the biopsy are positive for a lymph node metastasis, the preferred treatment is regional lymph node dissection. The parotid gland is involved in most of the patients with either lymphatic spread or direct invasion, so parotidectomy should be a part of neck dissection. ${ }^{9}$ For patients with nodal metastasis to the head and neck, adjuvant treatment options are based on both the number of positive nodes and presence or absence of extracapsular extension. ${ }^{9}$

\section{Melanoma}

Sentinel lymph node biopsy is one of the best strategies for melanomas to identify regional nodal disease, but it is not recommended for stage IA or IB lesions that are very thin $(0.75 \mathrm{~mm}$ or less $){ }^{10}$ Although there are some controversies, it is currently offered for patients with stage IB melanoma or stage II melanoma. ${ }^{10}$

When there is regional disease, a therapeutic neck dissection may be indicated. If the sentinel node is negative, regional lymph node dissection is not indicated. ${ }^{10}$ Patients presenting with clinically positive nodes without radiologic evidence of distant metastases should undergo complete lymph node dissection of the involved nodal region..$^{10}$ If there is a clinically or microscopically positive lymph nodes in the parotid gland in head and neck melanomas, a parotidectomy and appropriate neck dissection is recommended. ${ }^{10,46}$

\section{Merkel Cell Carcinoma}

Sentinel lymph node biopsy is very important in the staging and treatment of MCC, but because of the complex and variable drainage pattern of the head and neck, false negativity is a risk. ${ }^{42}$ Sentinel lymph node biopsy is offered to patients with clinical no disease for accurate nodal staging. ${ }^{42}$ If SLNB results are negative, observation is appropriate. ${ }^{42}$ If biopsy results are positive, imaging studies are recommended and if there is no distant metastasis lymph node dissection is recommended. ${ }^{42}$

\section{Reconstructive Planning}

Typically, once a full evaluation is complete, the surgeon will have a good foundation upon which to make a preliminary reconstructive plan. The reconstructive surgeon should make a plan for tumor clearance with 1 to $2 \mathrm{~cm}$ margins, which may be considered a "best-case scenario" and a "back-up plan" for positive peripheral and/or deep margins. Finally, the surgeon should consider a "worst-case scenario" during which multiple margins are positive or perineural spread, bone invasion, and/or unresectable disease is discovered.

Using the reconstructive algorithm, the surgeon then pursues the reconstructive plan with the best possible 
functional and cosmetic outcome with the least risk and donor site morbidity. All the possible complications and size of the defects and the reconstruction options should be discussed with the patient in detail and should be consented to before surgery. Finally, the patient's own goals should be reviewed, and expectations should be appropriately managed.

\section{Intraoperative Planning}

The resecting surgeon will prepare the patient for the tumor removal, margin analysis, and reconstruction. The patient should be re-evaluated at the time of surgery for any changes, spread or enlarged lymph nodes. At this time, planned cutaneous margins are marked out with at least $1 \mathrm{~cm}$ margins or greater for melanoma and/or sarcoma as indicated. Consideration should then be given to any prior scars as these may harbor tumor or may need to be incorporated into the resection margins. If the patient is to undergo parotidectomy or neck dissection and/or reconstruction with a locoregional or free flap, the patient will often require an extension beyond the tumor margins to facilitate exposure to lymph nodes or donor site vessels. It is crucial that such incisions extending beyond the margins of the tumor resection are not performed until margins are clear and/or the definitive reconstruction is determined. This avoids devascularization of a potential local flap that may be needed during the reconstruction.

Margins are then taken of peripheral skin, deep tissues, and any nerves or scar adjacent to the primary tumor. Once these are clear, the reconstruction may be performed. The final intraoperative assessment determines the ideal reconstruction, incorporating all important issues that are patient-specific, the total information accumulated during workup, and agreed upon goals. The tumor site defect is measured three dimensionally and the location and proximity to the eyelids, brow, nose, lips, and ear is determined. Examples of possible reconstructive options are then assessed and the ideal plan is pursued. The facial subunits and orientation of relaxed skin tension lines are important factors for facial reconstruction.

In general, once a skin cancer is assessed, measurements should be undertaken to achieve margin-free status. When possible, subunits should be resected and reconstructed separately so that the junctions between the different facial subunits do not overlap. The incisions should be placed within or parallel to skin tension lines or between subunit boundaries to have better cosmetic and functional results. Periorbital surgery requires collaborative input, with joint preparation involving both the ablative surgeon and reconstructive surgeon; this strategy helps to avoid postoperative lower lid malposition and ectropion.

\section{Reconstruction}

Reconstruction planning should begin at the time of diagnosis of skin cancer. The histology, growth rate, location, depth, extent, stage, and proximity to vital structures are key in determining the timing, type, donor site, functional, and cosmetic factors in the reconstruction. Definitive reconstruction of the defect from a primary excision is usually accomplished by applying basic principles of surgical reconstruction, using primary closure, secondary intention, a local flap, split-thickness skin graft (STSG) or full-thickness skin graft (FTSG), and/or a locoregional or free flap.

Choi et $\mathrm{al}^{5}$ reported that for their NMSC patients, primary closure was the most common method for repairing any surgical defect $(38.9 \%)$, followed by a local flap $(35.5 \%)$. In the same study, the coverage of BCC was performed most often by primary closure (39.5\%), followed by a local flap (34.2\%). The coverage of SCC was most commonly repaired by a local flap (39.5\%), followed by primary closure (34.2\%).

Reconstructive surgeons should be comfortable with the total tumor excision and surgical margins because residual tumor can have devastating problems. In melanoma, reconstruction should be delayed until permanent pathological examination of surgical margins is completed. Reconstructive efforts should start with the safest and least invasive methods of closure as healing by secondary intention, primary closure, skin grafting, local flaps, and free flaps.

\section{RECONSTRUCTION BY SITE}

Although reconstructive technical procedures are commonly performed with the same techniques, customizing the plan to the site of the cancer is more important in the face than other parts of the body due to the concentration of high-risk sites and complex structures.

\section{Scalp}

Reconstruction of the scalp presents unique difficulties that are not seen in other areas.

Scalp Cancer Complicating Factors:

- Limited mobility of scalp skin

- Proximity to cranial bone

- Cancer extension to bone and through cranial bone and suture lines

- Poor healing in radiated areas or in immunosuppressed patients.

Scalp tissue is relatively immobile, but by performing galeotomies, tissue stretching, and subgaleal undermining, defects smaller than $3 \mathrm{~cm}$ often can be closed primarily. Intermediate or larger defects can be reconstructed using two or more rotation flaps and the secondary defect 
might necessitate skin grafting. A FTSG is a good option to reconstruct large defects if there is a well-vascularized wound base with muscle and periosteum in nonradiated patients. In addition, the repair of the defect can be delayed to allow for filling the defect by granulation tissue, with the skin grafted at the time of a second operation. This will reduce the contour irregularity but there may still be a color and contour difference between a grafted region and adjacent region.

A secondary defect or lesions that have high risk of recurrence and require close monitoring might necessitate skin grafting. However, skin grafts are often unsuccessful when wounds have been radiated or when the outer cortex is devascularized. It is often important to use a burr to freshen the outer cortex to facilitate revascularization of skin grafts. To reconstruct larger defects, multiple rotation flaps are needed and ideally two or three rotation flaps are used.

If the scalp was radiated previously and has a large full thickness defect, or if the cranial bone requires resection, free flaps are the best options. The musculocutaneous or muscle-free flaps are typically bulky but these will naturally thin over time due to muscle atrophy, leading to an ideal contour. Anterior thigh and latissimus dorsi muscle-free flaps can be used for large defects and a STSG can also be combined with the muscle flap. ${ }^{47}$ If the scalp defect includes the full thickness of the cranium and is postradiated, a well-vascularized latissimus dorsi and scapula osseomyogenous flap can be used for fullthickness scalp and calvarial reconstruction. ${ }^{47,48}$ Bone reconstruction can also be carried out with synthetic materials, but the possibility of bacterial colonization in irradiated tissue and open malignant wounds should be kept in mind.

In general, the scalp is a difficult area to repair due to limited mobility of the skin and generally poor wound healing in radiated areas. Skin graft or local flaps are possible for small defects, but free tissue transfer is often required for larger areas, cranial bone defects, or radiated wounds.

\section{Nose}

Nasal reconstruction represents a particular challenge as it is an obvious part of the facial region and minor cosmetic changes are quite visible to others. Both the complex and personally unique anatomy of the skin, cartilage, and bony elements, in addition to the functional importance of nasal breathing, make it one of the more intricate functional and cosmetic reconstructions. The nose consists of three layers: An outer layer of skin, a support layer of bones and cartilage, and inner layers of mucosa and skin of the nasal vestibule. ${ }^{41}$ The excision of these layers ideally should be replaced with similar tissue.
The technique of the reconstruction should be decided based on size, shape, and thickness of the defects. The nose has well described esthetic subunits. ${ }^{41}$ The alar and facial-nasal sulcus should be preserved or reconstructed to optimize esthetic outcomes. The least favorable areas are the convex sites of the nasal dorsum and tip which tend to flatten when healing. ${ }^{41}$ Some of small defects in concave locations, such as medial canthus, medial cheek, and alar crease may be best left to heal by secondary intention. ${ }^{49,50}$

Primary closure may be an option when the defects are smaller than $1.5 \mathrm{~cm}$, located on dorsum or sidewalls. ${ }^{41}$ Any larger defects more than $1.5 \mathrm{~cm}$ will result in notching, deformities, and scarring. Superficial outer dorsum defects of the nose may only require a FTSGs but there are some concerns regarding esthetic outcomes. ${ }^{41}$ Jacobs et $\mathrm{al}^{51}$ compared the clinical appearance of wound healing after surgical repair with a skin graft $v$ s a skin flap for Mohs defects on the nose. Their conclusion was that while flap and graft repair may both be technically possible, a flap may be more likely to result in a superior cosmetic outcome.

Local flaps are best to match skin color, thickness, and shape of the defect area. Using healthy adjacent tissue results in the best esthetic outcomes. ${ }^{41,52}$ There are many variations of local flaps for reconstruction of the nose, such as bilobed flap, rhombic flap, advancement flap, dorsal nasal flap, transposition flap, and cervicofacial flap. The nasal dorsum and lateral nasal wall represent a relative tissue reservoir that can be used for transposition flaps. The bilobed flap is best used to repair skin defects in the lower third of the nose. ${ }^{41}$ Local flaps are not a good option for large defects or full-thickness nasal defects; regional flaps are a preferred option due to their blood supply. ${ }^{41}$ Regional flaps also provide more redundant skin and greater skin laxity. ${ }^{41}$ The most frequently used regional flaps are: Glabellar rotation flap, VY advancement cheek flap, finger flap, single-stage melolabial flap, paramedian/median forehead flap. The upper third of the nose and medial canthus can be adequately reconstructed with the classic glabellar flap or a finger flap. ${ }^{41} \mathrm{VY}$ advancement cheek flaps are good for nasal sidewalls in small or moderate defects but sometimes require a second surgery to restore the sulcus due to donor site nasofacial sulcus defect. ${ }^{41}$ Melolabial flaps are feasible for alar region and sidewall defects because of the minimal likelihood of donor site complications and good esthetic skin color match. ${ }^{41}$ Baker et $\mathrm{al}^{53}$ recommend two-stage surgery to avoid violation of the alar-facial sulcus. Mesolabial flaps are vulnerable to failure caused by random blood supply, radiation history, or smoking history. ${ }^{41}$

Forehead flaps are traditionally done via old flap technique but they can be successfully used for large and 
full-thickness nasal defects that are located throughout the nose. ${ }^{41,54}$ For this approach, Doppler ultrasonography is a necessary tool to localize the dominant blood artery which is supplied by supratrochlear artery. ${ }^{41}$ The ideal source of skin for nasal reconstruction comes from the forehead with a good color match and blood supply (Figs $1 \mathrm{~A}$ to $\mathrm{C}$ ).

In some advanced cases, rhinectomy defects may be more appropriately managed with a nasal prosthesis.

Nasal lining can be replaced by multiple steps and all grafts and flaps should be thin to allow for a functional airway. Conchal ear cartilage, septal cartilage, and rib cartilage can be good options to provide skeletal support. A composite auricular cartilage-skin graft can be used for reconstruction of both the internal lining and the cartilage. ${ }^{55}$ Skin replacement should be the final stage of any such reconstruction and options include skin grafts, folding the distal aspect of the cutaneous flap on itself, or septal mucosal flaps. ${ }^{41}$ The combination of ear grafts (skin-cartilage composite grafts for inner lining and framework) and local or regional flaps (outer covering) provides additional reconstructive options for selected nasal defects. ${ }^{55}$ If there is a need for a total reconstruction, a free flap for inner lining and an outer cover with a forehead flap could be employed. ${ }^{41}$

\section{Lip}

The vermilion border, the upper lip bow, and philtrum are the key esthetic subunits which are important for function and cosmesis. The upper lip has three subunits but the lower one has only one due to its embryological development; this should be considered when planning a reconstruction. ${ }^{41}$ The orbicularis oris muscle gives lips their bulkiness. The goals of the reconstruction of the lip are restoration of oral competence, preservation of sensation, acceptable esthetic, and avoidance of microstomia. ${ }^{41}$
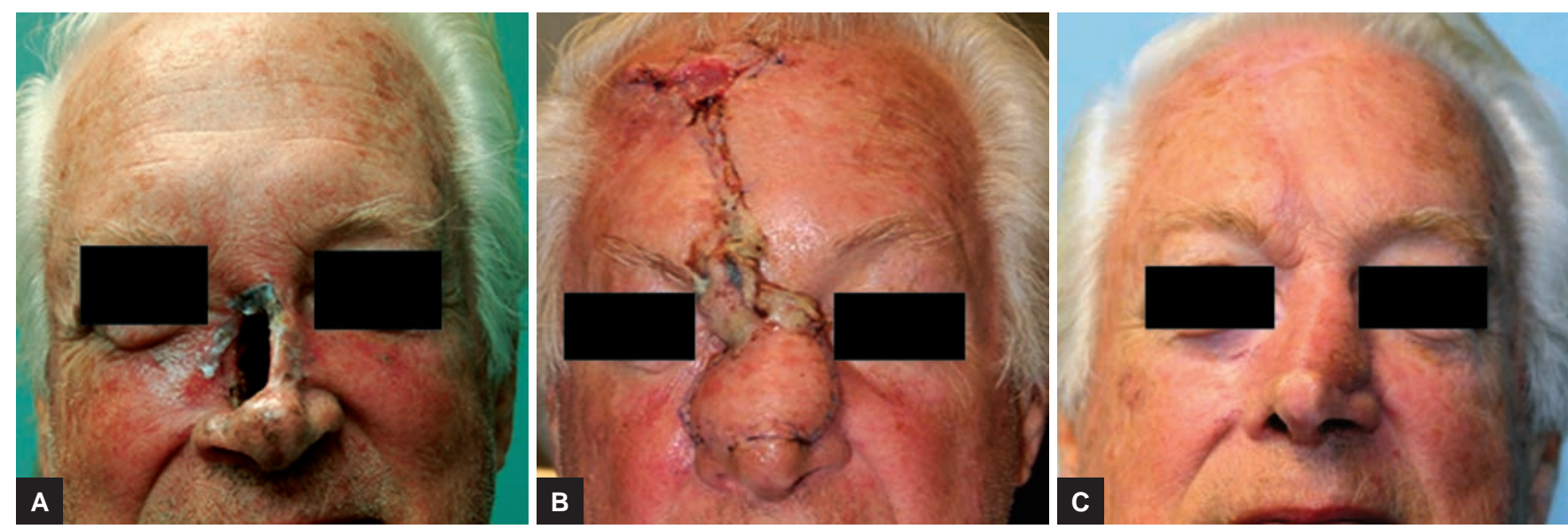

Figs 1A to C: A right full-thickness hemi-rhinectomy defect, reconstructed with paramedian forehead regional flap
If the vermillion is excised or any distortion in its original line can be recognized, a poor esthetic outcome is possible. ${ }^{41}$ Vermilion-only defects can be repaired with a facial artery musculomucosal flap. ${ }^{56}$ Defects up to one-third the length of the lower lip typically can be closed primarily as a V-shaped wedge resection. Primary closure requires closing mucosa, muscle, and skin as three separate layers, with precise realignment of the vermilion border. Carroll et $\mathrm{al}^{57}$ described a total lower lip reconstruction that can be achieved with a composite radial forearm-palmaris longus tendon free flap incorporating the palmaris longus tendon to provide a sling from which to suspend the reconstructed lower lip from each modiolus.

\section{Upper Lip}

The upper lip has less elasticity and has more important esthetic structures compared with the lower lip. Small defects can often be repaired with primary closure. Medium-sized defects can be closed with local rotation, advancement, and island flaps. If the defect is greater than one-third of the lip length, then it should be reconstructed with a flap and not closed primarily. Vermillion can be removed to the level of orbicular oris, and the mucosa advancement flaps can be used to close the defect and to relieve closure tension. Full-thickness upper lip defects that are less than one-third the size of the lip can usually be closed with a wedge excision or W-plasty. Lesions up to two-thirds the lip size are best closed with an abbe cross-lip flap or, if more laterally located, a melolabial advancement flap. Lesions of more than two-thirds the lip size can be addressed with bilateral advancement flaps with or without an additional abbe flap. Estlander originally rotated a lateral upperlip flap around the commissure to reconstruct a lateral lower-lip defect. ${ }^{58}$ The main disadvantage is rounding of the commissure, which might necessitate a subsequent commissuroplasty. 


\section{Lower Lip}

Lesions of up to one-third the size of the lip are best closed with a wedge excision or W-plasty (Figs 2A to C). Lesions that are one-third to two-thirds the lip size are best closed with cross-lip flaps or a Karapandzic flap. Lesions larger than two-thirds the lip size can be repaired with a free flap or bilateral abbe, submental island flap, bilateral Karapandzic, or a Bernard-Burrow-Webster flap. ${ }^{59-61}$ Extended Karapandzic flaps can be used to reconstruct near-total or total lower lip defects with innervated, well-vascularized tissues that recreate the oral sphincter and restore oral competence, but the main disadvantage is microstomia. ${ }^{59}$

\section{Forehead}

The forehead is bounded superiorly by the frontal hairline, laterally by temporal regions, and inferiorly by the supraorbital; it can be divided into three main parts as midline, paramedian, and lateral. Defects of the central one-third region are amenable to primary closure and subgaleal plane elevation can help to create an esthetic result. A skin crease can hide the scar which will be perpendicular to the skin tension lines. Tissue should be elevated in a subgaleal plane. If the defect cannot be closed directly, secondary intention can be a good option. In the paramedian and lateral regions, one or more advancement flaps provide the best esthetic result because the incisions can be placed in a horizontal orientation, parallel to the hairline, eyebrows, and forehead creases. Forehead tissue is relatively inelastic so bilateral advancement flaps can help to repair the defects by elevating a greater flap surface. However, the surgeon should avoid damaging the supraorbital and supratrochlear nerves and frontal branch of facial nerve while elevating the flap. Rotation flaps are not always a good option for forehead defects.

Defects involving 25 to $30 \%$ of the forehead region may be treated using a multistage approach involving initial stabilization of the wound with tissue expansion in the form of controlled prolonged expansion or rapid intraoperative expansion, whichever will provide the optimal reconstruction of form and function. ${ }^{62}$ Healing by secondary intention for skin grafts of the forehead should be used if the wound cannot be closed via other methods. Defects $>50 \%$ of the forehead surface area may be reconstructed with free flaps. Although adequate contour is feasible, color match is a common problem. Beasley et a ${ }^{47}$ suggested that a free revascularized tissue transfer is a reliable and safe way of reconstructing large forehead defects; a scapular free flap or latissimus dorsi free flap with STSG is the best option.

\section{Cheek}

The cheek covers a large area of the face, and is a common site for cutaneous malignancy. Adjacent regions of the cheek, such as nose, lip, and orbit as well as the size of the cheek defect should be evaluated together while planning the reconstruction of this site. If enough care is not given to the adjacent regions during reconstruction, it may result in excessive tension and scarring.

For achieving a good esthetic outcome, the primary closure incision should be planned parallel to the skin tension lines, using the skin laxity. A deep layer closure should be done adequately to ensure a relaxed skin closure. The medial cheek region can be repaired with primary closure but advancement flaps and rhomboid flaps both provide a good option for inferior medial cheek defects. Rotation flaps for larger defects can be used for reconstruction (Figs $3 \mathrm{~A}$ to $\mathrm{C}$ ).

The lateral cheek does not have the elasticity of the medial cheek. Therefore, smaller defects need to be repaired via transposition flaps and larger defects $(>3-4 \mathrm{~cm})$ can be reconstructed using rotation-advancement flaps that transfer large amounts of skin from the remaining cheek and upper neck tissue. Cook et $\mathrm{al}^{63}$ recommended cervicofacial rotation flaps for covering defects as large as $10 \mathrm{~cm}$.

Defects $>10 \mathrm{~cm}$ and full-thickness defects of the cheek can be reconstructed using free flaps from the anterolateral thigh, scapular region, or radial forearm. Color match and donor site morbidity must be factored into the decision. Free flaps have the ability to place a bulky volume on the defect that will help create a cosmetic cheek contour
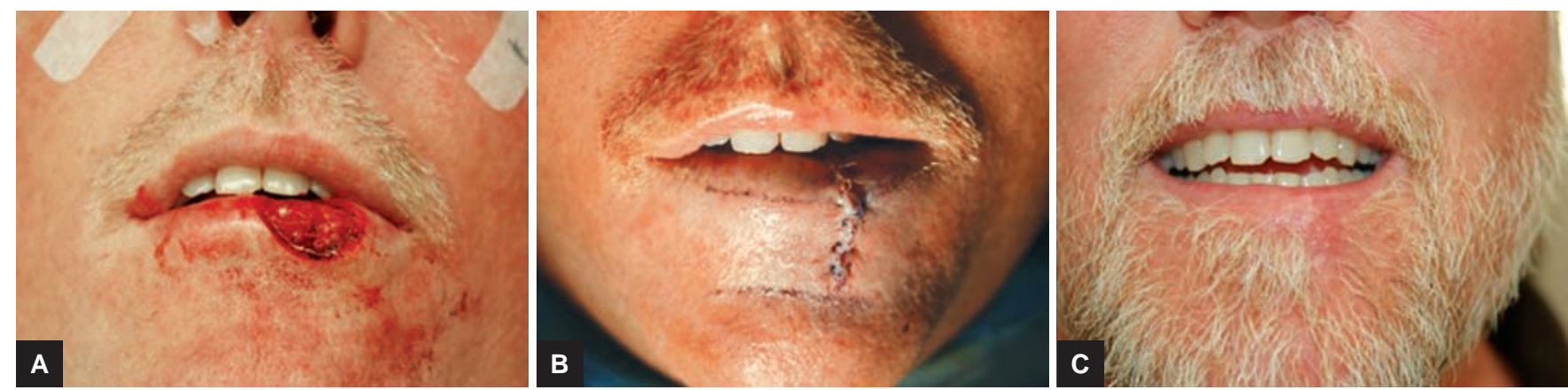

Figs 2A to C: A lower lip squamous cell carcinoma with a wedge excision, reconstructed with primary closure 

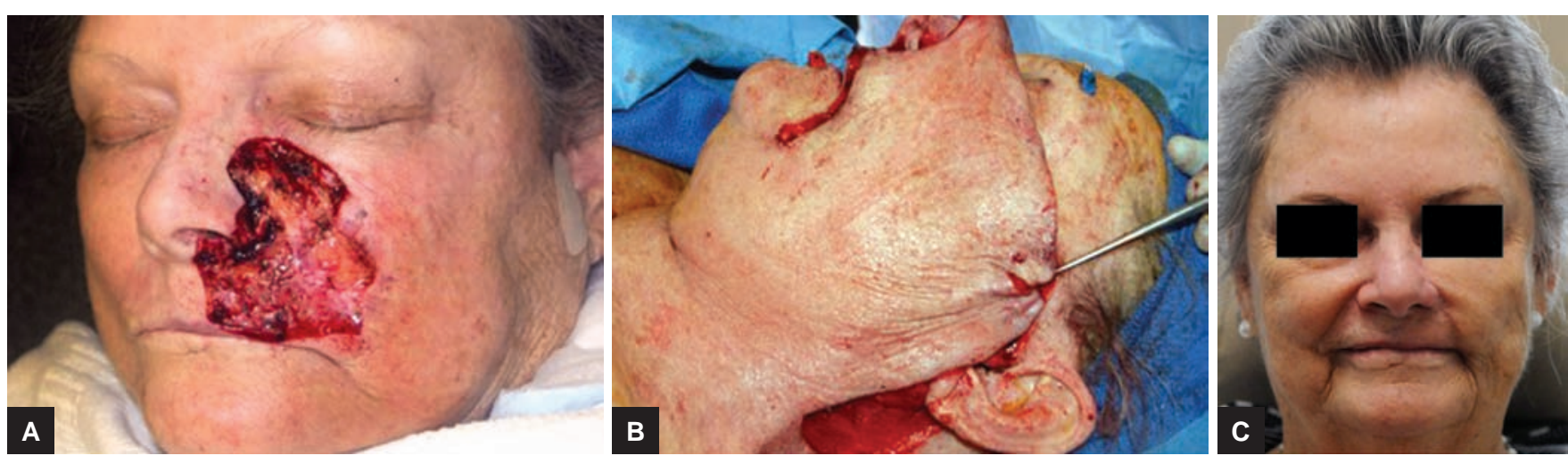

Figs 3A to C: A large defect from a medial cheek melanoma excision, reconstructed with a cervicofacial advancement flap and conchal composite for alar reconstruction

after the flap shrinks during the postoperative period. If the facial nerve is involved with the tumor and requires resection, interpositioning nerve grafts and/or static sling procedures can be good options. Parotid duct resection requires management via ligation or duct repositioning.

A radical parotidectomy defect can be repaired by a fasciocutaneous flap which provides bulk to restore cheek contour. Full-eye closure, facial symmetry, oral competence, nasal valve support, normal facial contour, appropriate skin color match, and eventual facial muscle tone are important points to achieve a good reconstruction. A fasciocutaneous flap provides bulk to restore cheek contour and replace skin defects and fascia. The tendons and motor nerve of the flap muscle contribute to the esthetic outcome of the repair. A gold weight is fixed to the tarsal plate of the upper lid.

\section{Eyelids}

The eyelids are complex trilaminar structures and awareness of the lacrimal drainage system is important for a functionally successful medial eyelid reconstruction. The best cosmetic and functional option will be achieved by direct closure and it can be applied to $\leq 50 \%$ defects. The surgeon should avoid ectropion and corneal irritation by stitches. If wound closure tension is excessive at the start, a lateral cantholysis can be performed. Anterior lamella-only defects are reconstructed more favorably with rhomboid or transposition local flaps and secondary intention healing is suitable for defects of the medial canthus $<1 \mathrm{~cm}$ in diameter. Larger full-thickness defects of the central or lateral eyelid can be repaired using an advancement flap.

\section{Ear}

Pinna defects can be reconstructed using local skin flaps if the defects are small. Larger defects should be reconstructed either by osseo-integrated prostheses or autologous constructs using combinations of rigid framework cartilage, temporoparietal fascia flaps, expanded local mastoid skin, and STSG. Defects of the conchal bowl and helical root are left to heal by secondary intention and subtotal conchal bowl defects can be repaired with a FTSG (Figs 4A and B). If exposed cartilage is devoid of perichondrium, the cartilage can be resected and the skin graft be applied to the medial auricular skin. Large defects involving lateral conchal bowl skin and cartilage
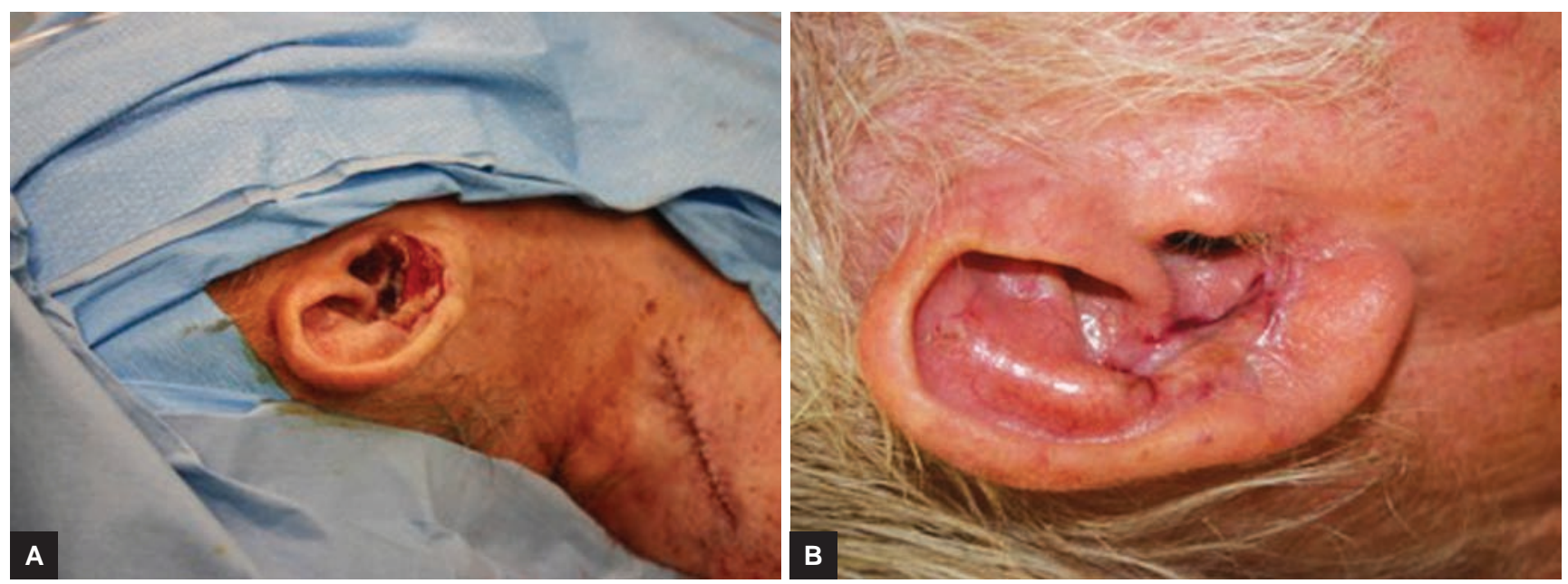

Figs 4A and B: A conchal bowl defect, reconstructed with a FTSG 
can be repaired using a postauricular subcutaneous tissue pedicle island advancement flap.

The superior one-third and the middle-third of the auricle can be closed primarily if the defect is $<1.5 \mathrm{~cm}$ in width. However, cupping of the ear should be avoided with primary closure. If the defect is limited to the helix and measures 1.5 to $2.5 \mathrm{~cm}$ in length, superior and inferior helical chondrocutaneous advancement flaps can be performed. Defects of $>2.5 \mathrm{~cm}$ confined to the helical rim should be considered for a preauricular or postauricular interpolated tubed flap. Up to half of the lobule can be resected as a wedge and closed primarily, owing to the laxity of skin, with minimal effect on esthetic outcomes. Total earlobe reconstruction requires two stages with two layers of closure. Skin sutures can be removed 5 to 7 days postoperatively. Steri-strips may be applied at the time of surgery to further reduce wound tension.

\section{Postoperative Considerations}

Patients with resection and reconstruction of facial skin cancers may be instructed on how to provide appropriate care to a wound that is healing through secondary intention or a wound reconstructed with skin graft, local flap, locoregional flap, and/or free tissue transfer. The patient should follow their physicians' advice on the use of wound ointments, cleaning, coverage, and care. Patients are advised to avoid sun exposure for 6 to 9 months postsurgery to prevent scar hyperpigmentation. Typically, the patient should see the operating surgeon within 1 to 3 weeks following surgery or sooner for any sign of infection, wound separation, fever, drainage, or other problems. In the appropriate patient, dermabrasion or laser resurfacing can be considered to optimize scar camouflage by smoothing and blending wound edges with surrounding skin. Finally, consultation with an experienced esthetician can help patients apply cosmetic products to further camouflage scars, as needed. Many reconstructive surgeons may offer secondary scar revision or cosmetic options as necessary and indicated after complete healing.

\section{SURVIVORSHIP AND SURVEILLANCE}

The skin cancer patients should be monitored well because 30 to $50 \%$ of NMSC patients may develop another NMSC within 5 years and they also have an increased risk of developing cutaneous melanoma. ${ }^{9,64}$ Therefore, continued long-term surveillance of these patients is essential, as is patient education about the value of sun protection and regular self-examination of the skin. The high-risk patients should be identified and carefully evaluated. The recurrence of SCC is mostly observed within 2 years of the initial therapy with 70 to $80 \%$ rates. ${ }^{9}$ Therefore, close follow-up of these patients during this time period is critical. Skin lesions in high-risk populations may be difficult to assess clinically, so skin biopsies of suspect lesions are necessary during follow-up.

There is no clear data to guide the follow-up of melanomas, but risk of recurrence is increased in patients with previous primary melanoma and/or family history of melanoma. Especially for these patients, the presence and extent of dysplastic nevi will impact the follow-up periods. ${ }^{10}$ Melanoma is most likely to recur in the first 5 years after the initial melanoma. In addition, patients cured of an initial primary melanoma are at increased risk for developing a second primary melanoma. ${ }^{10}$ Estimates of that increased risk range from 8 to $10 \%{ }^{10,65}$ Skin cancer preventive education should be promoted for patients with melanoma and their families. ${ }^{10}$ There is increasing evidence that regular sunscreen use may diminish the incidence of subsequent melanoma. ${ }^{66}$

Merkel cell carcinoma follow-up should include a complete skin and regional lymph node examination every 3 to 6 months for the first 2 years, then every 6 to 12 months thereafter; this can be individualized due to risk factors. ${ }^{42}$ The median time to recurrence in patients with MCC is about 8 months, with $90 \%$ of the recurrences occurring within 24 months. ${ }^{42}$

\section{CONCLUSION}

Cutaneous malignancies of the head and neck region mandate a multidisciplinary and coordinated approach to optimize cure while preserving and restoring cosmesis and function. This perioperative planning often falls on the responsibility of the treating surgeon who may be involved in the initial evaluation and treatment planning once a diagnosis is made. The functional and esthetic consequences of surgery of the face and head and region require a thoughtful approach to optimizing cure while also preparing for reconstruction.

Treatment of facial skin cancer requires a multidisciplinary evaluation and coordinated management which may involve a dermatologic Mohs trained surgeon, a head and neck oncologic surgeon, and a facial plastic and reconstructive surgeon in order to optimize patient care. Although patients often consider removal of a skin cancer, their primary concern, margin analysis, complete resection, parotid and cervical nodal management, and reconstruction play a vital role in achieving a cure while addressing functional and cosmetic issues. It is recommended that proper diagnosis, staging, and full treatment (including reconstruction) planning be completed before starting interventions in this important and complex region. 


\section{REFERENCES}

1. Cancer Facts and Figures 2016. American Cancer Society [Accessed 2016 Jun 14]. Available from: http:/ / www.cancer. org/acs/groups/content/@research/documents/document/ acspc-047079.pdf.

2. Makin J. Implications of climate change for skin cancer prevention in Australia. Health Promot J Austr 2011 Dec;22 Spec No:S39-S41.

3. Rogers HW, Weinstock MA, Feldman SR, Coldiron BM. Incidence estimate of nonmelanoma skin cancer (Keratinocyte Carcinomas) in the U.S. population, 2012. JAMA Dermatol 2015 Oct;151(10):1081-1086.

4. Ouyang YH. Skin cancer of the head and neck. Semin Plast Surg 2010 May;24(2):117-126.

5. Choi JH, Kim YJ, Kim H, Nam SH, Choi YW. Distribution of Basal cell carcinoma and squamous cell carcinoma by facial esthetic unit. Arch Plast Surg 2013 Jul;40(4):387-391.

6. Mydlarz WK, Weber RS, Kupferman ME. Cutaneous malignancy of the head and neck. Surg Oncol Clin N Am 2015 Jul;24(3):593-613.

7. Larson DL, Larson JD. Head and neck melanoma. Clin Plast Surg 2010 Jan;37(1):73-77.

8. Youl PH, Janda M, Aitken JF, Del Mar CB, Whiteman DC, Baade PD. Body-site distribution of skin cancer, pre-malignant and common benign pigmented lesions excised in general practice. Br J Dermatol 2011 Jul;165(1):35-43.

9. NCCN Clinical Practice Guidelines in Oncology (NCCN Guidelines ${ }^{\circledR}$ ) Squamous Cell Carcinoma of Skin. 7th ed. [Accessed 2016 Jun 20]. Available from: https:/ /www.nccn. org/professionals/physician_gls/pdf/squamous.pdf.

10. NCCN Clinical Practice Guidelines in Oncology (NCCN Guidelines ${ }^{\circledR}$ ) Melanoma. 7th ed. [Accessed 2016 Jun 20]. http:/ / www.nccn.org/professionals/physician_gls/pdf/ melanoma.pdf.

11. IARC monographs on the evaluation of carcinogenic risks to humans. Solar and ultraviolet radiation. IARC Monogr Eval Carcinog Risks Hum 1992;55:1-316.

12. Trakatelli M, Ulrich C, del Marmol V, Euvrard S, Stockfleth E, Abeni D. Epidemiology of nonmelanoma skin cancer (NMSC) in Europe: accurate and comparable data are needed for effective public health monitoring and interventions. Br J Dermatol 2007 May;156 (Suppl 3):1-7.

13. Karagas MR, Nelson HH, Zens MS, Linet M, Stukel TA, Spencer S, Applebaum KM, Mott L, Mabuchi K. Squamous cell and basal cell carcinoma of the skin in relation to radiation therapy and potential modification of risk by sun exposure. Epidemiology 2007 Nov;18(6):776-784.

14. Gurudutt VV, Genden EM. Cutaneous squamous cell carcinoma of the head and neck. J Skin Cancer 2011;2011:502723.

15. Gourin CG, Terris DJ. Head and neck cancer in transplant recipients. Curr Opin Otolaryngol Head Neck Surg 2004 Apr;12(2):122-126.

16. Saini AT, Miles BA. Merkel cell carcinoma of the head and neck: pathogenesis, current and emerging treatment options. Onco Targets Ther 2015 Aug 19;8:2157-2167.

17. McIntosh BC, Narayan D. Head and neck angiosarcomas. J Craniofac Surg 2005 Jul;16(4):699-703.

18. Alsaad KO, Obaidat NA, Ghazarian D. Skin adnexal neoplasms - part 1: an approach to tumours of the pilosebaceous unit. J Clin Pathol 2007 Feb;60(2):129-144.
19. Obaidat NA, Alsaad KO, Ghazarian D. Skin adnexal neoplasms - part 2: an approach to tumours of cutaneous sweat glands. J Clin Pathol 2007 Feb;60(2):145-159.

20. Baxi S, Deb S, Weedon D, Baumann K, Poulsen M. Microcystic adnexal carcinoma of the skin: the role of adjuvant radiotherapy. J Med Imaging Radiat Oncol 2010 Oct;54(5): 477-482.

21. Erovic BM, Goldstein DP, Kim D, Al Habeeb A, Waldron J, Ghazarian D, Irish JC. Sebaceous gland carcinoma of the head and neck: the Princess Margaret Hospital experience. Head Neck 2013 Mar;35(3):316-320.

22. Nonaka D, Bishop PW. Sarcoma-like tumor of head and neck skin. Am J Surg Pathol 2014 Jul;38(7):956-965.

23. Miller K, Goodlad JR, Brenn T. Pleomorphic dermal sarcoma: adverse histologic features predict aggressive behavior and allow distinction from atypical fibroxanthoma. Am J Surg Pathol 2012 Sep;36(9):1317-1326.

24. Russell EB, Carrington PR, Smoller BR. Basal cell carcinoma: a comparison of shave biopsy versus punch biopsy techniques in subtype diagnosis. J Am Acad Dermatol 1999 Jul;41(1):69-71.

25. Austin JR, Byers RM, Brown WD, Wolf P. Influence of biopsy on the prognosis of cutaneous melanoma of the head and neck. Head Neck 1996 Mar-Apr;18(2):107-117.

26. NCCN Clinical Practice Guidelines in Oncology (NCCN Guidelines ${ }^{\circledR}$ ) Basal Cell Carcinoma. 7th ed. [Accessed 2016 Jun 20]. Available from: https:/ / www.nccn.org/professionals/ physician_gls/pdf/nmsc.pdf.

27. Smeets NW, Krekels GA, Ostertag JU, Essers BA, Dirksen CD, Nieman FH, Neumann HA. Surgical excision vs Mohs' micrographic surgery for basal-cell carcinoma of the face: randomised controlled trial. Lancet 2004 Nov 13-19;364(9447): 1766-1772.

28. Wolf DJ, Zitelli JA. Surgical margins for basal cell carcinoma. Arch Dermatol 1987 Mar;123(3):340-344.

29. Brodland DG, Zitelli JA. Surgical margins for excision of primary cutaneous squamous cell carcinoma. J Am Acad Dermatol 1992 Aug;27(2 Pt 1):241-248.

30. Kauvar AN, Arpey CJ, Hruza G, Olbricht SM, Bennett R. Consensus for nonmelanoma skin cancer treatment, part II: squamous cell carcinoma, including a cost analysis of treatment methods. Dermatol Surg 2015 Nov;41(11):1214-1240.

31. Huang CC, Boyce SM. Surgical margins of excision for basal cell carcinoma and squamous cell carcinoma. Semin Cutan Med Surg 2004 Sep;23(3):167-173.

32. Leibovitch I, Huilgol SC, Selva D, Hill D, Richards S, Paver R. Cutaneous squamous cell carcinoma treated with Mohs micrographic surgery in Australia I. Experience over 10 years. J Am Acad Dermatol 2005 Aug;53(2):253-260.

33. Jacobsen AA,AldahanAS,HughesOB,Shah VV,StrasswimmerJ. Hedgehog pathway inhibitor therapy for locally advanced and metastatic basal cell carcinoma: a systematic review and pooled analysis of interventional studies. JAMA Dermatol 2016 Jul 1;152(7):816-824.

34. Petit JY, Avril MF, Margulis A, Chassagne D, Gerbaulet A, Duvillard P, Auperin A, Rietjens M. Evaluation of cosmetic results of a randomized trial comparing surgery and radiotherapy in the treatment of basal cell carcinoma of the face. Plast Reconstr Surg 2000 Jun;105(7):2544-2551.

35. Mark RJ, Poen J, Tran LM, Fu YS, Selch MT, Parker RG. Postirradiation sarcomas. A single-institution study and review of the literature. Cancer 1994 May 15;73(10):2653-2662. 
36. Jang JW, Chan AW. Prevention and management of complications after radiotherapy for skull base tumors: a multidisciplinary approach. Adv Otorhinolaryngol 2013;74:163-173.

37. Porceddu SV. Prognostic factors and the role of adjuvant radiation therapy in non-melanoma skin cancer of the head and neck. Am Soc Clin Oncol Educ Book 2015:e513-e518.

38. Doepker MP, Thompson ZJ, Fisher KJ, Yamamoto M, Nethers KW, Harb JN, Applebaum MA, Gonzalez RJ, Sarnaik AA, Messina JL, et al. Is a wider margin $(2 \mathrm{~cm}$ vs. $1 \mathrm{~cm})$ for a 1.01-2.0 mm melanoma necessary? Ann Surg Oncol 2016 Jul;23(7):2336-2342.

39. Wagner JD, Gordon MS, Chuang TY, Coleman JJ 3rd. Current therapy of cutaneous melanoma. Plast Reconstr Surg 2000 Apr;105(5):1774-1799; quiz 1800-1801.

40. Watson J. Love and caring. Ethics of face and hand - an invitation to return to the heart and soul of nursing and our deep humanity. Nurs Adm Q 2003 Jul-Sep;27(3):197-202.

41. Eskiizmir G, Baker S, Cingi C. Nonmelanoma skin cancer of the head and neck: reconstruction. Facial Plast Surg Clin North Am 2012 Nov;20(4):493-513.

42. NCCN Clinical Practice Guidelines in Oncology (NCCN Guidelines ${ }^{\circledR}$ ). Mercel Cell Carcinoma. 7th ed. [Accessed 2016 Jun 20]. Available from: https://www.nccn.org/professionals/physician_gls/pdf/mcc.pdf.

43. Stratigos A, Garbe C, Lebbe C, Malvehy J, del Marmol V, Pehamberger H, Peris K, Becker JC, Zalaudek I, Saiag P, et al. Diagnosis and treatment of invasive squamous cell carcinoma of the skin: European consensus-based interdisciplinary guideline. Eur J Cancer 2015 Sep;51(14):1989-2007.

44. Silberstein E, Sofrin E, Bogdanov-Berezovsky A, Nash M, Segal N. Lymph node metastasis in cutaneous head and neck squamous cell carcinoma. Dermatol Surg 2015 Oct;41(10): 1126-1129.

45. Navarrete-Dechent C, Veness MJ, Droppelmann N, Uribe P. High-risk cutaneous squamous cell carcinoma and the emerging role of sentinel lymph node biopsy: a literature review. J Am Acad Dermatol 2015 Jul;73(1):127-137.

46. Pathak I, O'Brien CJ, Petersen-Schaeffer K, McNeil EB, McMahon J, Quinn MJ, Thompson JF, McCarthy WH. Do nodal metastases from cutaneous melanoma of the head and neck follow a clinically predictable pattern? Head Neck 2001 Sep;23(9):785-790.

47. Beasley NJ, Gilbert RW, Gullane PJ, Brown DH, Irish JC, Neligan PC. Scalp and forehead reconstruction using free revascularized tissue transfer. Arch Facial Plast Surg 2004 Jan-Feb;6(1):16-20.

48. Ch'ng S, Clark JR. The scapular angle adds versatility to the latissimus dorsi free flap in complicated scalp reconstruction. J Plast Reconstr Aesthet Surg 2011 Sep;64(9):e248-e249.

49. Zitelli JA. Wound healing by secondary intention. A cosmetic appraisal. J Am Acad Dermatol 1983 Sep;9(3):407-415.

50. van der Eerden PA, Lohuis PJ, Hart AA, Mulder WC, Vuyk H. Secondary intention healing after excision of nonmelanoma skin cancer of the head and neck: statistical evaluation of prognostic values of wound characteristics and final cosmetic results. Plast Reconstr Surg 2008 Dec;122(6):1747-1755.
51. Jacobs MA, Christenson LJ, Weaver AL, Appert DL, Phillips PK, Roenigk RK, Otley CC. Clinical outcome of cutaneous flaps versus full-thickness skin grafts after Mohs surgery on the nose. Dermatol Surg 2010;36(1):23-30.

52. Chu EA, Byrne PJ. Local flaps I: bilobed, rhombic, and cervicofacial. Facial Plast Surg Clin North Am 2009 Aug;17(3):349-360.

53. Baker SR, Johnson TM, Nelson BR. The importance of maintaining the alar-facial sulcus in nasal reconstruction. Arch Otolaryngol Head Neck Surg 1995 Jun;121(6):617-622.

54. Boyd CM, Baker SR, Fader DJ, Wang TS, Johnson TM. The forehead flap for nasal reconstruction. Arch Dermatol 2000 Nov;136(11):1365-1370.

55. Keck T, Lindemann J, Kuhnemann S, Sigg O. Healing of composite chondrocutaneous auricular grafts covered by skin flaps in nasal reconstructive surgery. Laryngoscope 2003 Feb;113(2):248-253.

56. Pribaz JJ, Meara JG, Wright S, Smith JD, Stephens W, Breuing KH. Lip and vermilion reconstruction with the facial artery musculomucosal flap. Plast Reconstr Surg 2000 Mar;105(3):864-872.

57. Carroll CM, Pathak I, Irish J, Neligan PC, Gullane PJ. Reconstruction of total lower lip and chin defects using the composite radial forearm - palmaris longus tendon free flap. Arch Facial Plast Surg 2000 Jan-Mar;2(1):53-56.

58. Alvarez GS, Siqueira EJ, de Oliveira MP. A new technique for reconstruction of lower-lip and labial commissure defects: a proposal for the association of Abbe-Estlander and vermilion myomucosal flap techniques. Oral Surg Oral Med Oral Pathol Oral Radiol 2013 Jun;115(6):724-730.

59. Hanasono MM, Langstein HN. Extended Karapandzic flaps for near-total and total lower lip defects. Plast Reconstr Surg 2011 Mar;127(3):1199-1205.

60. Kim JP, Park HW, Park JJ, Woo SH. Reconstruction after resection of a lower lip squamous cell carcinoma with a submental island flap. Ear Nose Throat J 2015 Dec;94(12):E19-E21.

61. Brinca A, Andrade P, Vieira R, Figueiredo A. Karapandzic flap and Bernard-Burrow-Webster flap for reconstruction of the lower lip. An Bras Dermatol 2011 Jul-Aug;86(4 Suppl 1): S156-S159.

62. Baker SR, Swanson NA. Reconstruction of midfacial defects following surgical management of skin cancer. The role of tissue expansion. J Dermatol Surg Oncol 1994 Feb;20(2):133-140.

63. Cook TA, Israel JM, Wang TD, Murakami CS, Brownrigg PJ. Cervical rotation flaps for midface resurfacing. Arch Otolaryngol Head Neck Surg 1991 Jan;117(1):77-82.

64. Chen J, Ruczinski I, Jorgensen TJ, Yenokyan G, Yao Y, Alani R, Liégeois NJ, Hoffman SC, Hoffman-Bolton J, Strickland PT, et al. Nonmelanoma skin cancer and risk for subsequent malignancy. J Natl Cancer Inst 2008 Sep 3;100(17):1215-1222.

65. Ferrone CR, Ben Porat L, Panageas KS, Berwick M, Halpern AC, Patel A, Coit DG. Clinicopathological features of and risk factors for multiple primary melanomas. JAMA 2005 Oct;294(13): 1647-1654.

66. Green AC, Williams GM, Logan V, Strutton GM. Reduced melanoma after regular sunscreen use: randomized trial follow-up. J Clin Oncol 2011 Jan 20;29(3):257-263. 